\title{
In-depth haemodynamic phenotyping of pulmonary hypertension due to left heart disease
}

\author{
Christian Gerges ${ }^{1}$, Mario Gerges ${ }^{1}$, Pierre Fesler ${ }^{2}$, Anna Maria Pistritto ${ }^{3}$, \\ Nicholas P. Konowitz ${ }^{1}$, Johannes Jakowitsch ${ }^{1}$, David S. Celermajer ${ }^{4}$ and \\ Irene M. Lang ${ }^{1}$
}

Affiliations: ${ }^{1}$ Dept of Internal Medicine II, Division of Cardiology, Vienna General Hospital, Medical University of Vienna, Vienna, Austria. ${ }^{2}$ PhyMedExp, University of Montpellier, CNRS, INSERM and Dept of Internal Medicine Lapeyronie, CHU Montpellier, Montpellier, France. ${ }^{3}$ Dept of Internal Medicine, Division of Cardiology, Ferrarotto Hospital, University of Catania, Catania, Italy. ${ }^{4}$ Dept of Cardiology, Sydney Medical School, University of Sydney, Sydney, Australia.

Correspondence: Irene Lang, Dept of Internal Medicine II, Division of Cardiology, Medical University of Vienna, Währinger Gürtel 18-20, 1090 Vienna, Austria. E-mail: irene.langdmeduniwien.ac.at

@ERSpublications

Combined post- and pre-capillary $\mathrm{PH}$ is characterised by pre-capillary pulmonary vascular disease and a positive response to inhaled NO http://ow.ly/G2nF30iYTeJ

Cite this article as: Gerges C, Gerges M, Fesler P, et al. In-depth haemodynamic phenotyping of pulmonary hypertension due to left heart disease. Eur Respir J 2018; 51: 1800067 [https://doi.org/10.1183/ 13993003.00067-2018].

ABSTRACT The commonest cause of pulmonary hypertension (PH) is left heart disease (LHD). The current classification system for definitions of PH-LHD is under review. We therefore performed prospective in-depth invasive haemodynamic phenotyping in order to assess the site of increased pulmonary vascular resistance (PVR) in PH-LHD subsets.

Based on pulmonary artery occlusion waveforms yielding an estimate of the effective capillary pressure, we partitioned PVR in larger arterial (Rup, upstream resistance) and small arterial plus venous components ( $R \mathrm{ds}$, downstream resistance). In the case of small vessel disease, $R$ up decreases and $R \mathrm{ds}$ increases. Inhaled nitric oxide (NO) testing was used to assess acute vasoreactivity.

Right ventricular afterload (PVR, pulmonary arterial compliance and effective arterial elastance) was significantly higher in combined post- and pre-capillary $\mathrm{PH}(\mathrm{Cpc}-\mathrm{PH}, \mathrm{n}=35)$ than in isolated postcapillary PH (Ipc-PH, n=20). Right ventricular afterload decreased during inhalation of NO in $\mathrm{Cpc}-\mathrm{PH}$ and idiopathic pulmonary arterial hypertension $(n=31)$, but remained unchanged in Ipc-PH. Rup was similar in $\mathrm{Cpc}-\mathrm{PH}(66.8 \pm 10.8 \%)$ and idiopathic pulmonary arterial hypertension $(65.0 \pm 12.2 \% ; \mathrm{p}=0.530)$ suggesting small vessel disease, but significantly higher in Ipc-PH $(96.5 \pm 4.5 \% ; \mathrm{p}<0.001)$ suggesting upstream transmission of elevated left atrial pressure.

Right ventricular afterload is driven by elevated left atrial pressure in Ipc-PH and is further increased by elevated small vessel resistance in $\mathrm{Cpc-PH}$. Cpc- $\mathrm{PH}$ is responsive to inhaled NO. Our data support current definitions of PH-LHD subsets. 


\section{Introduction}

The most common subset of pulmonary hypertension (PH) is $\mathrm{PH}$ due to left heart disease (LHD), resulting from left ventricular dysfunction (systolic and/or diastolic) and/or left-sided valvular heart disease [1]. PH-LHD is the consequence of an upstream transmission of elevated left atrial pressure (LAP). In $13 \%$ of cases with PH-LHD an increase in mean pulmonary arterial pressure (mPAP) occurs that is disproportionate to LAP due to an additional contribution of "pre-capillary" pulmonary vascular disease, which results in decreased right ventricular-pulmonary vascular coupling and has been associated with increased mortality [2-5]. Such patients can be identified by an elevated diastolic pulmonary vascular pressure gradient $(\mathrm{DPG}) \geqslant 7 \mathrm{mmHg}$. At present, the prognostic relevance of DPG has been both supported [5-11] and refuted [12-14]. Currently, PH-LHD is classified in the European Society of Cardiology/ European Respiratory Society guidelines as either 1) "isolated post-capillary PH" (Ipc-PH; DPG $<7 \mathrm{mmHg}$ and/or pulmonary vascular resistance (PVR) $\leqslant 3$ Wood units (WU)) or 2) "combined post- and pre-capillary PH" (Cpc-PH; DPG $\geqslant 7 \mathrm{mmHg}$ and/or PVR $>3 \mathrm{WU}$ ) [15].

The effective capillary pressure of the pulmonary circulation $\left(P_{c^{\prime}}\right)$ can be estimated based on the PAP decay curve after balloon occlusion (figure 1) [16]. Using $P_{c^{\prime}}$, PVR can be partitioned into larger arterial (upstream, Rup) and small arterial plus venous (downstream, $R \mathrm{ds}$ ) components [16-19]. In healthy subjects PVR follows an almost equal distribution across the pulmonary circulation with $\sim 60 \% R$ up and $\sim 40 \% R \mathrm{ds}$ [20]. In idiopathic pulmonary arterial hypertension (iPAH) there is a similar PVR partitioning pattern, yet a significant elevation in $\mathrm{mPAP}$ and $P_{\mathrm{c}^{\prime}}$ has been described. This has been explained by the fact that $P_{\mathrm{c}^{\prime}}$ is increased because small arterial remodelling extends to the capillary-venous compartment [16]. In chronic thromboembolic pulmonary hypertension (CTEPH) pulmonary artery occlusion waveform analysis has been employed to differentiate between central and peripheral pulmonary vascular obstruction [21, 22] . We sought to partition PVR at baseline and after inhalation of nitric oxide (NO) in patients with PH-LHD.

\section{Methods}

\section{Study population}

We prospectively enrolled 265 patients (figure 2). The ethics committee of the Medical University of Vienna approved the study and all patients signed informed consents (approval 1496/2012). Patients underwent a first diagnostic right heart catheterisation, vasoreactivity testing, pulmonary artery occlusion waveform analysis and left heart catheterisation, including coronary angiography and left ventricular end-diastolic pressure measurement, as previously described [4, 23]. Catheterisations were performed for various indications, mostly for the diagnosis of elevated systolic PAP (sPAP) on echocardiography, in patients with chronic heart failure and/or in patients with suspected $\mathrm{PH}$, but also prior to valve replacements, percutaneous interventions and surgical procedures. A diagnosis of heart failure was

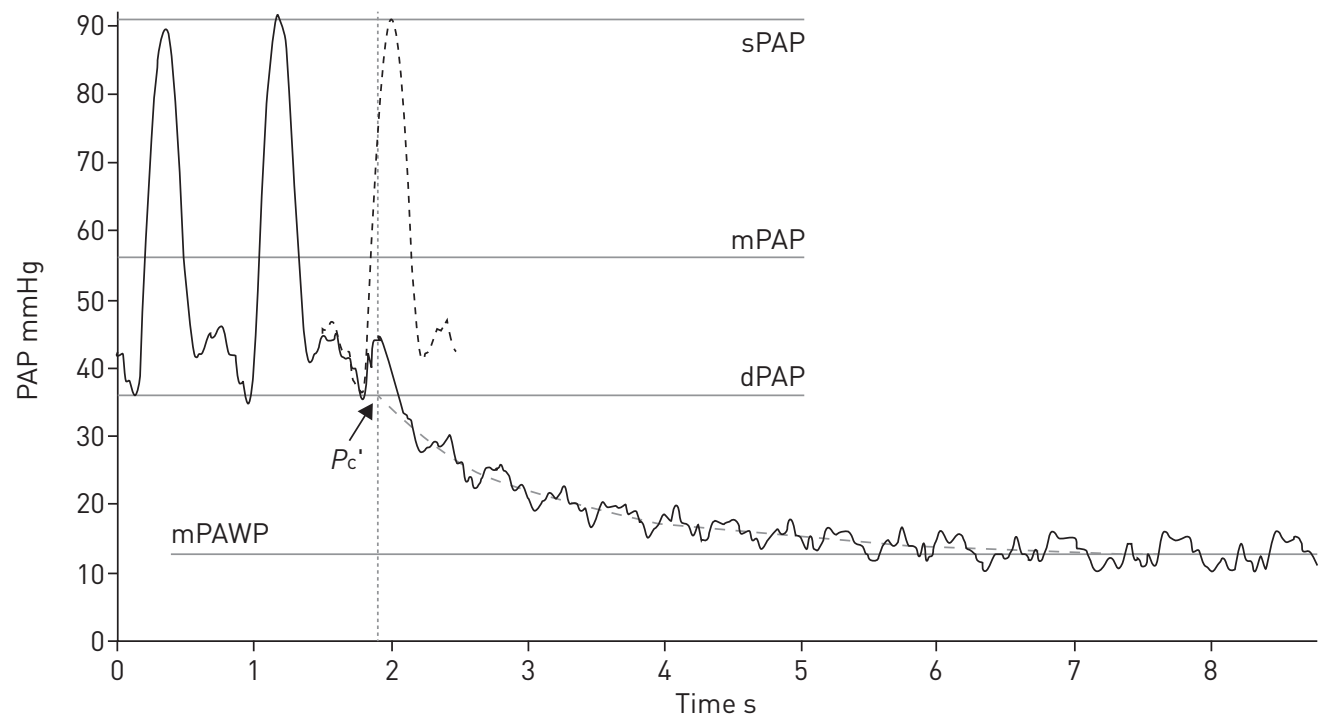

FIGURE 1 Pulmonary artery occlusion waveform. PAP: pulmonary arterial pressure; sPAP: systolic PAP; mPAP: mean PAP; dPAP: diastolic PAP. Pressure decay curve between the moment of occlusion lvertical dotted line) and the recording of mean pulmonary arterial wedge pressure (mPAWP) for the assessment of pressure in pre-capillary small pulmonary arteries and pulmonary capillaries $\left(P_{\mathrm{c}^{\prime}}\right)$. 


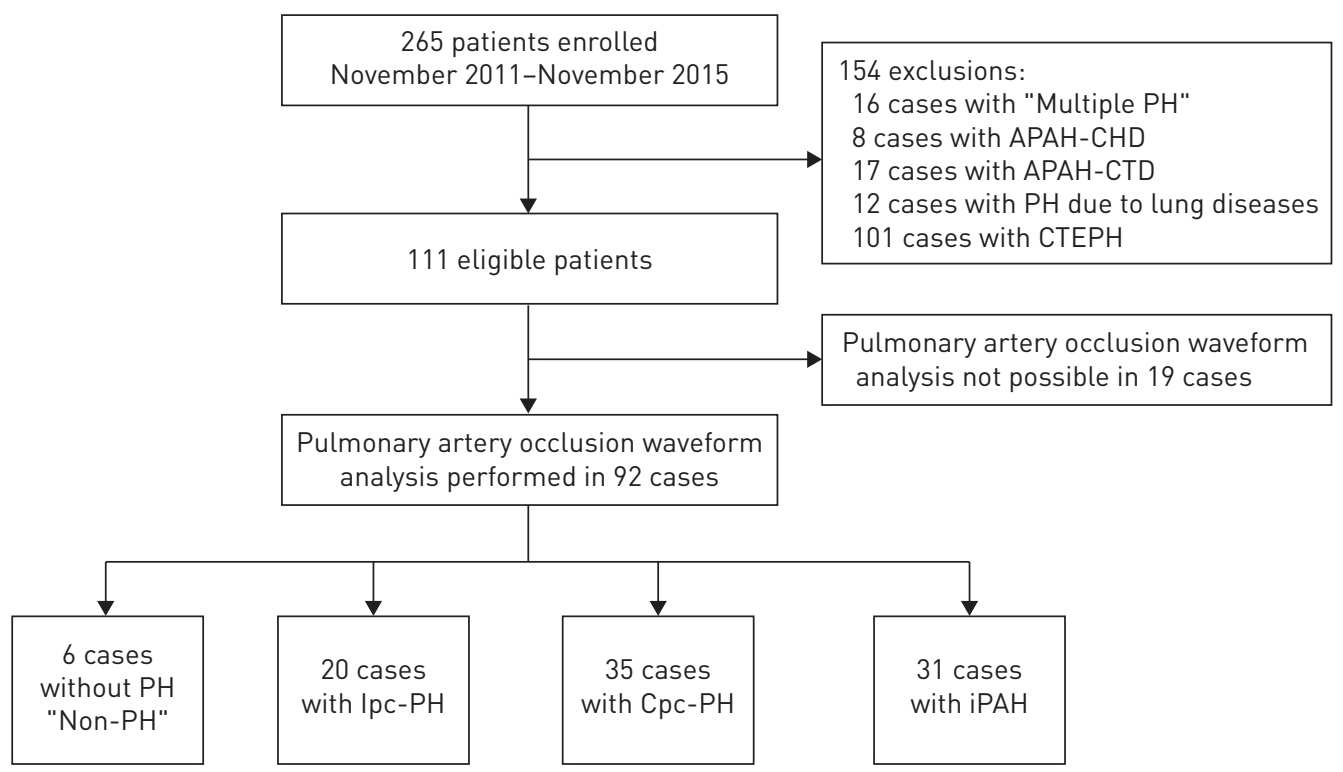

FIGURE 2 Patient disposition. PH: pulmonary hypertension; PAH: pulmonary arterial hypertension; APAH-CHD: PAH associated with congenital heart disease; APAH-CTD: PAH associated with connective tissue disease; $\mathrm{CTEPH}$ : chronic thromboembolic $\mathrm{PH}$; $\mathrm{lpc}-\mathrm{PH}$ : isolated post-capillary $\mathrm{PH}$; $\mathrm{Cpc}-\mathrm{PH}$ : combined postand pre-capillary $\mathrm{PH}$; iPAH: idiopathic $\mathrm{PAH} .265$ patients were prospectively enrolled in our study. Pulmonary artery occlusion waveform analysis was not possible in 19 patients because of atrial fibrillation/arrhythmia. 92 patients were available for final analyses. Of those, six subjects had normal pulmonary haemodynamics ("Non-PH"), 20 patients had Ipc-PH, 35 patients had $\mathrm{Cpc}-\mathrm{PH}$ and 31 patients had $\mathrm{iPAH}$.

independently adjudicated according to the current heart failure guidelines of the European Society of Cardiology and the American College of Cardiology Foundation/American Heart Association [24, 25]. Patients with heart failure due to constrictive pericarditis and due to infiltrative, restrictive or hypertrophic cardiomyopathy were excluded. Patients were on specific and optimised heart failure treatments, at their physician's discretion, but none were taking $\mathrm{PH}$-specific drugs.

\section{Haemodynamic assessment and vasoreactivity testing}

Haemodynamics were obtained at rest and during inhalation of $20 \mathrm{ppm}$ NO (inhaled NO (iNO)). For haemodynamic assessment, a 7-French Swan-Ganz catheter (Edwards Lifesciences, Irvine, CA, USA) was inserted from a femoral or jugular venous approach. Mean right atrial pressure, right ventricular pressure, sPAP, diastolic PAP (dPAP) and mPAP, mean pulmonary arterial wedge pressure (mPAWP), and respective oxygen saturations, including inferior and superior vena cava saturations, were measured. Left ventricular end-diastolic pressure (LVEDP) was measured via femoral arterial access with a 7-French pigtail catheter (Cordis, Bridgewater, NY, USA). All pressures were recorded as averages of eight timepressure integral derivations during several respiratory cycles using the Sensis system (Siemens, Berlin, Germany) [26]. Zero reference was at the mid-thoracic level [26]. Cardiac output (CO) was assessed in triplicate by thermodilution. With the catheter in the pulmonary artery, patients were given $20 \mathrm{ppm}$ iNO via a continuous positive airway pressure mask under continuous flow oxygen at $2 \mathrm{~L} \cdot \mathrm{min}^{-1}$ (Pulmonox-Mini; Messer-Griesheim, Vienna, Austria) for $5 \mathrm{~min}$ before a complete haemodynamic assessment was repeated. iNO administration was continued during these measurements. A positive classic response to iNO was defined as a reduction of $\mathrm{mPAP} \geqslant 10 \mathrm{mmHg}$ to an absolute value of $\mathrm{mPAP}$ $\leqslant 40 \mathrm{mmHg}$ with increased or unchanged $\mathrm{CO}$ [15]. A nonclassic response was defined as a reduction of $\mathrm{mPAP} \geqslant 10 \mathrm{mmHg}$ without a drop below an absolute $\mathrm{mPAP}$ value of $40 \mathrm{mmHg}$ [27].

\section{Haemodynamic definitions}

The transpulmonary gradient (TPG) was calculated by subtracting mPAWP from mPAP. DPG was calculated as the difference between dPAP and mPAWP $[2,28,29]$. PVR was calculated by dividing TPG by $\mathrm{CO}$ and expressed in Wood units (WU; $\mathrm{mmHg} \cdot \mathrm{min} \cdot \mathrm{L}^{-1}$ ). CPA was defined as stroke volume divided by pulmonary pulse pressure (difference between sPAP and dPAP). The pulmonary vascular resistancecompliance time (RC-time; the product of PVR and CPA, expressed in milliseconds) was estimated as previously described [30]. The effective arterial elastance $(E \mathrm{a})$ was calculated as the ratio of mPAP to stroke volume. 
Partitioning of pulmonary vascular resistance

Pulmonary artery occlusion waveforms were recorded at $250 \mathrm{~Hz}$ during breath-hold at end-expiration over $\sim 8$ s. Pressure signals were filtered using a two-pole digital low-pass filter with a cut-off at $18 \mathrm{~Hz}$. Measurements were performed in triplicate with an average difference in Rup of $4 \pm 2 \%$. A biexponential fitting of the pressure decay curve between the moment of occlusion and mPAWP, with normalisation to mPAP, was performed in order to assess $P_{\mathrm{c}^{\prime}}$ (a surrogate of zero flow pressure $\left(P_{\mathrm{zf}}\right)$ ) (figure 1) $[16,31$, 32]. Using $P_{c^{\prime}}$, PVR was partitioned into larger arterial (upstream, Rup) and small arterial plus venous (downstream, $R \mathrm{ds}$ ) components. Rup was assessed as $\left(\mathrm{mPAP}-P_{\mathrm{c}^{\prime}}\right) /(\mathrm{mPAP}-\mathrm{mPAWP}) \times 100$. Pulmonary artery occlusion waveforms from patients with atrial fibrillation and other forms of arrhythmia at the time of haemodynamic assessment were excluded $(n=19)$ (figure 2$)$.

\section{PH definitions and subset classification}

The $\mathrm{PH}$ guidelines distinguish the following haemodynamic definitions during measurements at rest, without iNO and oxygen: 1) "Non-PH" with mPAP $<25 \mathrm{mmHg}$, 2) pre-capillary $\mathrm{PH}$ with mPAP $\geqslant 25 \mathrm{mmHg}$ and mPAWP $\leqslant 15 \mathrm{mmHg}$, and 3 ) post-capillary $\mathrm{PH}$ with $\mathrm{mPAP} \geqslant 25 \mathrm{mmHg}$ and mPAWP $>15 \mathrm{mmHg}$ [15].

Post-capillary $\mathrm{PH}$ was classified as either 1 ) Ipc-PH (mPAP $\geqslant 25 \mathrm{mmHg}, \mathrm{mPAWP}>15 \mathrm{mmHg}$, DPG $<7 \mathrm{mmHg}$ and/or PVR $\leqslant 3 \mathrm{WU}$ ) or 2) $\mathrm{Cpc}-\mathrm{PH}$ ( $\mathrm{mPAP} \geqslant 25 \mathrm{mmHg}, \mathrm{mPAWP}>15 \mathrm{mmHg}$, DPG $\geqslant 7 \mathrm{mmHg}$ and PVR $>3 \mathrm{WU}$ ) $[15,33]$. Moderate to severe and severe left-sided echocardiographic ventricular and valvular heart disease were assessed as probable causes of $\mathrm{PH}$.

Ventilation-perfusion lung scintigraphy, multidetector computed tomography, lung function tests (including spirometry and diffusion capacity measurements) and pulmonary angiography were performed to exclude CTEPH, chronic obstructive pulmonary disease and interstitial lung disease. PAH associated with congenital heart disease, connective tissue disease or portal hypertension as well as CTEPH or PH due to interstitial lung disease (moderate to severe) and/or chronic obstructive pulmonary disease (Global Initiative for Obstructive Lung Disease stage 3 or 4) and/or obstructive sleep apnoea syndrome and simultaneous LHD were classified as "combinations of diagnoses" or "Multiple-PH". Patients with "Multiple-PH", PAH associated with congenital heart disease or connective tissue disease, $\mathrm{PH}$ due to lung diseases and/or hypoxia, and CTEPH were excluded from the study (n=154) (figure 2).

\section{Statistical analysis}

Adherence to a Gaussian distribution was determined using the Kolmogorov-Smirnov test. Normally distributed data were described as mean with standard deviation and the independent samples t-test was utilised to compare continuous variables between two groups, while the paired-sample t-test was used to compare differences within groups. In case of skewed distribution, data were described as median and interquartile range. One-way ANOVA with correction for multiple pairwise comparisons using the Bonferroni method was applied to assess differences across several groups. Qualitative variables were described as number and percentage. The strength of association between quantitative variables was measured with Spearman's rank correlation coefficient. Data were analysed with SPSS Statistics version 21 for Mac (IBM, Armonk, NY, USA). All p-values are results from two-sided tests, with significance inferred at $\mathrm{p}<0.05$.

\section{Results}

\section{Patients}

92 patients fulfilled the pre-specified study criteria (figure 2). Six subjects had normal pulmonary haemodynamics ("Non-PH"), 31 patients were diagnosed with iPAH and 55 were classified as having PH-LHD: 20 with Ipc-PH and 35 with $\mathrm{Cpc}-\mathrm{PH}$ (figure 2). Clinical characteristics are given in table 1. LVEDP was measured in all patients for validation of mPAWP. Bland-Altman analysis showed that LVEDP was on average $2.6 \mathrm{mmHg}$ lower than mPAWP, with limits of agreement ranging from -7.6 to $2.4 \mathrm{mmHg}$ in patients with PH-LHD. Larger differences between mPAWP and LVEDP were found in patients with mitral valve disease (one patient with severe mitral stenosis and four patients with mitral regurgitation).

\section{Right ventricular afterload}

Haemodynamics of the whole study population at rest and after iNO are given in table 2. Despite similar mPAWP $(25.3 \pm 8.2$ versus $21.1 \pm 3.4 \mathrm{mmHg} ; \mathrm{p}=0.064)$, baseline right ventricular afterload was significantly higher in Cpc-PH (PVR 6.4 $\pm 3.5 \mathrm{WU}$ and $E \mathrm{a} 0.8 \pm 0.4 \mathrm{mmHg} \cdot \mathrm{mL}^{-1}$ ) compared with Ipc-PH (PVR $3.1 \pm 1.3 \mathrm{WU} ; \mathrm{p}<0.001$ and $\left.E \mathrm{a} 0.6 \pm 0.2 \mathrm{mmHg} \cdot \mathrm{mL}^{-1} ; \mathrm{p}=0.031\right)$. Right ventricular afterload was highest in $\mathrm{iPAH}$ (table 2, and figure $3 \mathrm{a}$ and $\mathrm{b}$ ). 
TABLE 1 Clinical characteristics

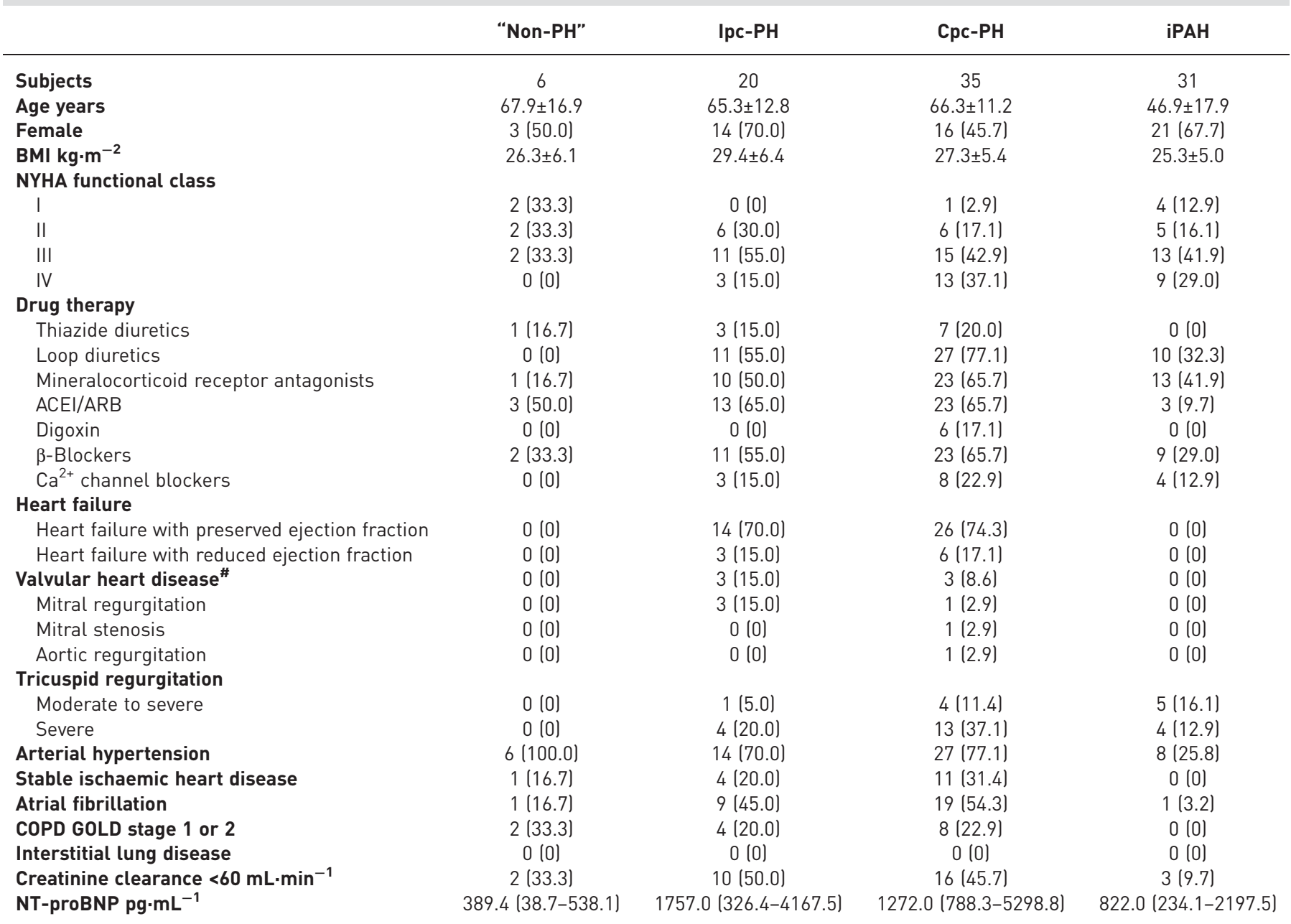

Data are presented as $\mathrm{n}$, mean $\pm \mathrm{SD}, \mathrm{n}(\%)$ or median (interquartile range). $\mathrm{PH}$ : pulmonary hypertension; Ipc- $\mathrm{PH}$ : isolated post-capillary $\mathrm{PH}$; $\mathrm{Cpc}-\mathrm{PH}$ : combined post- and pre-capillary PH; iPAH: idiopathic pulmonary arterial hypertension; BMI: body mass index; NYHA: New York Heart Association; ACEI: angiotensin converting enzyme inhibitor; ARB: angiotensin receptor blocker; COPD: chronic obstructive pulmonary disease; GOLD: Global Initiative for Chronic Obstructive Lung Disease; NT-proBNP: N-terminal pro-brain natriuretic peptide. ${ }^{\#}$ : moderate to severe or severe valvular heart disease.

\section{Estimates of small pulmonary artery and capillary pressure}

$P_{\mathrm{c}^{\prime}}$ was significantly different between groups (ANOVA; $\mathrm{p}<0.001$ ) and significantly higher in $\mathrm{Cpc}-\mathrm{PH}$ $(31.3 \pm 8.2 \mathrm{mmHg})$ than in Ipc-PH $(26.6 \pm 8.3 \mathrm{mmHg} ; \mathrm{p}=0.026)$ and "Non-PH" $(12.8 \pm 2.0 \mathrm{mmHg} ; \mathrm{p}<0.001)$, but similar to values observed in iPAH $(29.2 \pm 9.4 \mathrm{mmHg} ; \mathrm{p}=0.365)$ (table 2). $P_{\mathrm{c}^{\prime}}$ was significantly higher than $\mathrm{mPAWP}$ in all groups. However, $P_{\mathrm{c}^{\prime}}$ to $\mathrm{mPAWP}$ gradients were larger in iPAH (mean $20.7 \mathrm{mmHg}$, 95\% CI 17.2 to $24.3 \mathrm{mmHg}$; $<0.001)$ and $\mathrm{Cpc}-\mathrm{PH}(10.2 \mathrm{mmHg}, 95 \%$ CI 8.4 to $12.0 \mathrm{mmHg}$; $<0.001)$ than in "Non-PH" (3.2 mmHg, 95\% CI 2.2 to $8.3 \mathrm{mmHg}$; $\mathrm{p}=0.009)$. In Ipc-PH, the difference between $P_{c^{\prime}}$ and mPAWP was small $(1.3 \mathrm{mmHg}, 95 \%$ CI 0.7 to $1.9 \mathrm{mmHg}$; $<<0.001)$. $P_{\mathrm{c}^{\prime}}$ correlated significantly with mPAWP in all groups. The strongest correlations were found in Ipc-PH $(r=0.989 ; \mathrm{p}<0.001)$ and "Non- $\mathrm{PH}$ " $(\mathrm{r}=0.900 ; \mathrm{p}=0.037)$. Correlations were weaker in $\mathrm{Cpc}-\mathrm{PH}(\mathrm{r}=0.787 ; \mathrm{p}<0.001)$ and $\mathrm{PAH}(\mathrm{r}=0.496 ; \mathrm{p}=0.005)$.

During NO inhalation, a significant decrease in $P_{c^{\prime}}$ was observed in $\mathrm{Cpc}-\mathrm{PH}(-2.6 \mathrm{mmHg}, 95 \% \mathrm{CI}-5.0$ to $-0.2 \mathrm{mmHg}$; $=0.025)$ and $\mathrm{iPAH}(-4.4 \mathrm{mmHg}, 95 \% \mathrm{CI}-6.9$ to $-1.9 \mathrm{mmHg} ; \mathrm{p}=0.007)$, while $P_{\mathrm{c}^{\prime}}$ increased significantly in Ipc-PH $(3.4 \mathrm{mmHg}, 95 \%$ CI 0.4 to $6.4 \mathrm{mmHg} ; \mathrm{p}=0.014)$ and did not change in "Non-PH" (-1.4 mmHg, 95\% CI -8.3 to $5.4 \mathrm{mmHg}$; $=0.458$ ) (table 2).

\section{Upstream resistance}

Rup in $\mathrm{Cpc}-\mathrm{PH}$ was similar $(66.8 \pm 10.8 \%)$ to that seen in iPAH $(65.0 \pm 12.2 \%$; $=0.530)$ and "Non-PH" $(62.4 \pm 4.6 \% ; \mathrm{p}=0.385)$. In contrast, Rup was significantly higher in Ipc-PH $(96.5 \pm 4.5 \% ; \mathrm{p}<0.001)$ than in 
TABLE 2 Haemodynamic characteristics at baseline and after inhaled nitric oxide (iNO)

\begin{tabular}{|c|c|c|c|c|c|c|c|c|}
\hline & \multicolumn{2}{|c|}{ “Non-PH" } & \multicolumn{2}{|c|}{ Ipc-PH } & \multicolumn{2}{|c|}{ Сpc-PH } & \multicolumn{2}{|c|}{ iPAH } \\
\hline Subjects & \multicolumn{2}{|c|}{6} & \multicolumn{2}{|c|}{20} & \multicolumn{2}{|c|}{35} & \multicolumn{2}{|c|}{31} \\
\hline $\mathrm{CO} L \cdot \mathrm{min}^{-1}$ & $5.9 \pm 1.0$ & $6.0 \pm 1.0$ & $5.6 \pm 2.2$ & $5.4 \pm 1.4$ & $5.0 \pm 1.3$ & $5.5 \pm 1.4^{\pi}$ & $4.6 \pm 1.1$ & $4.9 \pm 1.2^{91}$ \\
\hline SVR WU & $14.2 \pm 0.6^{\#}$ & $14.2 \pm 3.7^{\#}$ & $16.0 \pm 5.3$ & $16.6 \pm 7.2$ & $18.3 \pm 6.9$ & $17.0 \pm 5.9$ & $19.0 \pm 5.8$ & $19.6 \pm 5.0$ \\
\hline mRAP mmHg & $5.4 \pm 3.0^{\#}$ & $7.2 \pm 1.9^{\#}$ & $12.6 \pm 5.5^{\#}$ & $12.9 \pm 7.8$ & $15.8 \pm 4.9$ & $15.9 \pm 7.6$ & $9.5 \pm 4.7^{\#}$ & $8.5 \pm 4.2^{\#}$ \\
\hline LVEDP $\mathrm{mmHg}$ & $11.0 \pm 4.1^{\#}$ & $8.0 \pm 2.6^{\#}$ & $23.0 \pm 7.3$ & $24.8 \pm 8.5^{\pi}$ & $19.1 \pm 5.5$ & $20.2 \pm 3.9^{9}$ & $9.6 \pm 3.3^{\#}$ & $9.3 \pm 8.2^{\#}$ \\
\hline$P_{\mathrm{c}^{\prime}} \mathrm{mmHg}$ & $12.8 \pm 2.0^{\#}$ & $13.0 \pm 2.8^{\#}$ & $26.6 \pm 8.3^{\#}$ & $29.4 \pm 8.6^{\text {ๆ }}$ & $31.3 \pm 8.2$ & $28.7 \pm 8.4^{9}$ & $29.2 \pm 9.4$ & $24.6 \pm 9.1^{\pi}$ \\
\hline Ea $\mathrm{mmHg} \cdot \mathrm{mL}^{-1}$ & $0.3 \pm 0.1^{\#}$ & $0.2 \pm 0.0^{\#}$ & $0.6 \pm 0.2^{\#}$ & $0.6 \pm 0.3$ & $0.8 \pm 0.4$ & $0.6 \pm 0.3^{9}$ & $1.0 \pm 0.4$ & $0.8 \pm 0.4^{\# .9}$ \\
\hline PVR WU & $2.1 \pm 0.4^{\#}$ & $1.6 \pm 0.6^{\#}$ & $3.1 \pm 1.3^{\#}$ & $3.2 \pm 1.4$ & $6.4 \pm 3.5$ & $4.2 \pm 2.3^{\pi}$ & $10.8 \pm 4.2^{\#}$ & $7.9 \pm 4.2^{\# .9}$ \\
\hline$C_{\text {PA }} \mathrm{mL} \cdot \mathrm{mmHg}^{-1}$ & $3.5 \pm 1.4^{\#}$ & $5.4 \pm 1.8^{\#, \text {. }}$ & $2.4 \pm 0.9^{\#}$ & $2.5 \pm 1.4$ & $2.0 \pm 1.4$ & $2.4 \pm 1.6^{\text {ก }}$ & $1.4 \pm 0.8^{\#}$ & $1.8 \pm 1.0^{\circ}$ \\
\hline RC-time ms & $445 \pm 189^{\#}$ & $493 \pm 204$ & $405 \pm 152^{\#}$ & $397 \pm 138$ & $588 \pm 190$ & $447 \pm 158^{\pi}$ & $764 \pm 331^{\#}$ & $693 \pm 200^{\#}$ \\
\hline
\end{tabular}

Data are presented as $\mathrm{n}$ or mean $\pm \mathrm{SD}$. $\mathrm{PH}$ : pulmonary hypertension; Ipc-PH: isolated post-capillary $\mathrm{PH}$; $\mathrm{Cpc}-\mathrm{PH}$ : combined post- and pre-capillary $\mathrm{PH}$; iPAH: idiopathic pulmonary arterial hypertension; CO: cardiac output; SVR: systemic vascular resistance; WU: Wood units; mRAP: mean right atrial pressure; mPAP: mean pulmonary arterial pressure; mPAWP: mean pulmonary arterial wedge pressure; LVEDP: left ventricular end-diastolic pressure; $P_{c^{\prime}}$ : effective capillary pressure; $E$ a: effective arterial elastance; PVR: pulmonary vascular resistance; $C$ PA: pulmonary arterial compliance; RC-time: PVR-compliance time (product of PVR and CPA); Rup: upstream resistance; TPG: transpulmonary gradient; DPG: diastolic pulmonary vascular pressure gradient. \#: $p<0.05$, compared with values in $\mathrm{Cpc}-\mathrm{PH}$ using the independent samples $t$-test; ${ }^{\text {१: }} p<0.05$, compared with baseline values within the same group using the paired samples t-test.

Cpc-PH (table 2 and figure 3c). Rup correlated strongly with DPG ( $\mathrm{r}=-0.797 ; \mathrm{p}<0.001)$ in PH-LHD (figure 4a). Correlations between Rup and TPG ( $\mathrm{r}=-0.467 ; \mathrm{p}<0.001)$, PVR $(\mathrm{r}=-0.495 ; \mathrm{p}<0.001)$ and CPA $(\mathrm{r}=0.279 ; \mathrm{p}=0.039)$ were only weak (figure $4 \mathrm{~b}-\mathrm{d})$.

During NO inhalation, Rup increased significantly in $\mathrm{Cpc}-\mathrm{PH}$ (by $8.0 \%, 95 \%$ CI $2.2 \%$ to $13.8 \%$; $\mathrm{p}=0.032$ ) and in $\mathrm{iPAH}$ (by $6.4 \%, 95 \% \mathrm{CI} 2.6 \%$ to $10.2 \%$; $=0.005$ ), indicating a decrease of distal vascular resistance (table 2 and figure $5 \mathrm{c}$ ). In contrast, Rup did not change in Ipc-PH $(-0.9 \%, 95 \%$ CI $-4.0 \%$ to $2.3 \%$; $\mathrm{p}=0.534)$ and "Non-PH" $(0.4 \%, 95 \% \mathrm{CI}-3.1 \%$ to $3.9 \%$; $=0.974)$ (table 2 and figure $5 \mathrm{c}$ ).

\section{Response to iNO}

Patients with $\mathrm{Cpc}-\mathrm{PH}$ and iPAH showed significant improvements in CO, mPAP, PVR, CPA, TPG and DPG during inhalation of NO (table 2, supplementary tables SA and SB, and figure $5 \mathrm{a}$ and b). In contrast, only an isolated increase of mPAWP occurred in Ipc-PH (table 2). In "Non-PH", CPA increased significantly during NO inhalation (table 2). Three iPAH patients (9.7\%) and three $\mathrm{Cpc}-\mathrm{PH}$ patients (8.6\%) fulfilled classic "haemodynamic responder" criteria. In nine patients with iPAH (29.0\%), five patients with Cpc-PH (14.3\%) and one patient with Ipc-PH (5.0\%), mPAP dropped by $\geqslant 10 \mathrm{mmHg}$ but not $\leqslant 40 \mathrm{mmHg}$ (nonclassic response). None of the patients with Ipc-PH and "Non-PH" fulfilled classic responder criteria.

Supplementary tables SA and SB show relative changes from baseline under iNO in Ipc- $\mathrm{PH}, \mathrm{Cpc}-\mathrm{PH}$ and iPAH stratified by haemodynamic responder status. In classic responders with $\mathrm{Cpc}-\mathrm{PH}(\mathrm{n}=3), \mathrm{mPAP}$ decreased by $33 \pm 17 \%$ (from $43.7 \pm 6.8$ to $30.0 \pm 11.4 \mathrm{mmHg}$; $\mathrm{p}=0.036$ ), $\mathrm{CO}$ increased by $33 \pm 18 \%$ (from 5.6 \pm 2.1 to $7.0 \pm 1.9 \mathrm{~L} \cdot \mathrm{min}^{-1} ; \mathrm{p}=0.018$ ) and PVR decreased by $55 \pm 8 \%$ (from $5.1 \pm 2.4$ to $2.1 \pm 0.6 \mathrm{WU}$; $\mathrm{p}=0.005$ ). In iPAH $(\mathrm{n}=3$ ), mPAP decreased by $42 \pm 5 \%$ (from $51.0 \pm 11.4$ to $29.3 \pm 6.8 \mathrm{mmHg} ; \mathrm{p}=0.021$ ) and PVR decreased by $53 \pm 9 \%$ (from $11.2 \pm 5.1$ to $5.6 \pm 3.6 \mathrm{WU}$; $\mathrm{p}=0.021$ ), while $\mathrm{CO}$ remained unchanged ( $3 \pm 5 \%$; from $5.6 \pm 2.1$ to $7.0 \pm 1.9 \mathrm{~L} \cdot \mathrm{min}^{-1} ; \mathrm{p}=0.423$ ).

In nonclassic responders with Cpc-PH $(n=5)$, mPAP decreased by $4 \pm 13 \%$ (from $68.3 \pm 9.0$ to $50.5 \pm 7.3 \mathrm{mmHg} ; \mathrm{p}=0.002$ ) and PVR decreased by $17 \pm 32 \%$ (from $11.9 \pm 4.8$ to $5.7 \pm 3.2 \mathrm{WU}$; $\mathrm{p}=0.007$ ), while CO remained unchanged ( $4 \pm 15 \%$; from $4.2 \pm 1.2$ to $\left.4.4 \pm 1.4 \mathrm{~L} \cdot \mathrm{min}^{-1} ; \mathrm{p}=0.275\right)$. In iPAH ( $\left.\mathrm{n}=9\right)$, mPAP decreased by $7 \pm 9 \%$ (from $63.6 \pm 9.2$ to $49.3 \pm 8.0 \mathrm{mmHg}$; $\mathrm{p}<0.001$ ), $\mathrm{CO}$ increased by $9 \pm 13 \%$ (from $4.8 \pm 0.9$ to $5.3 \pm 1.0 \mathrm{~L} \cdot \mathrm{min}^{-1} ; \mathrm{p}=0.016$ ) and PVR decreased by $19 \pm 14 \%$ (from $11.4 \pm 2.0$ to $7.5 \pm 2.1 \mathrm{WU} ; \mathrm{p}<0.001$ ).

In nonresponders with $\mathrm{Cpc}-\mathrm{PH}(\mathrm{n}=27)$, PVR decreased by $17 \pm 32 \%$ (from $5.3 \pm 2.3$ to $4.3 \pm 2.1 \mathrm{WU}$; $\mathrm{p}=0.011$ ), while CO remained unchanged ( $4 \pm 15 \%$; from $5.3 \pm 1.1$ to $\left.5.5 \pm 1.2 \mathrm{~L} \cdot \mathrm{min}^{-1} ; \mathrm{p}=0.292\right)$. The 

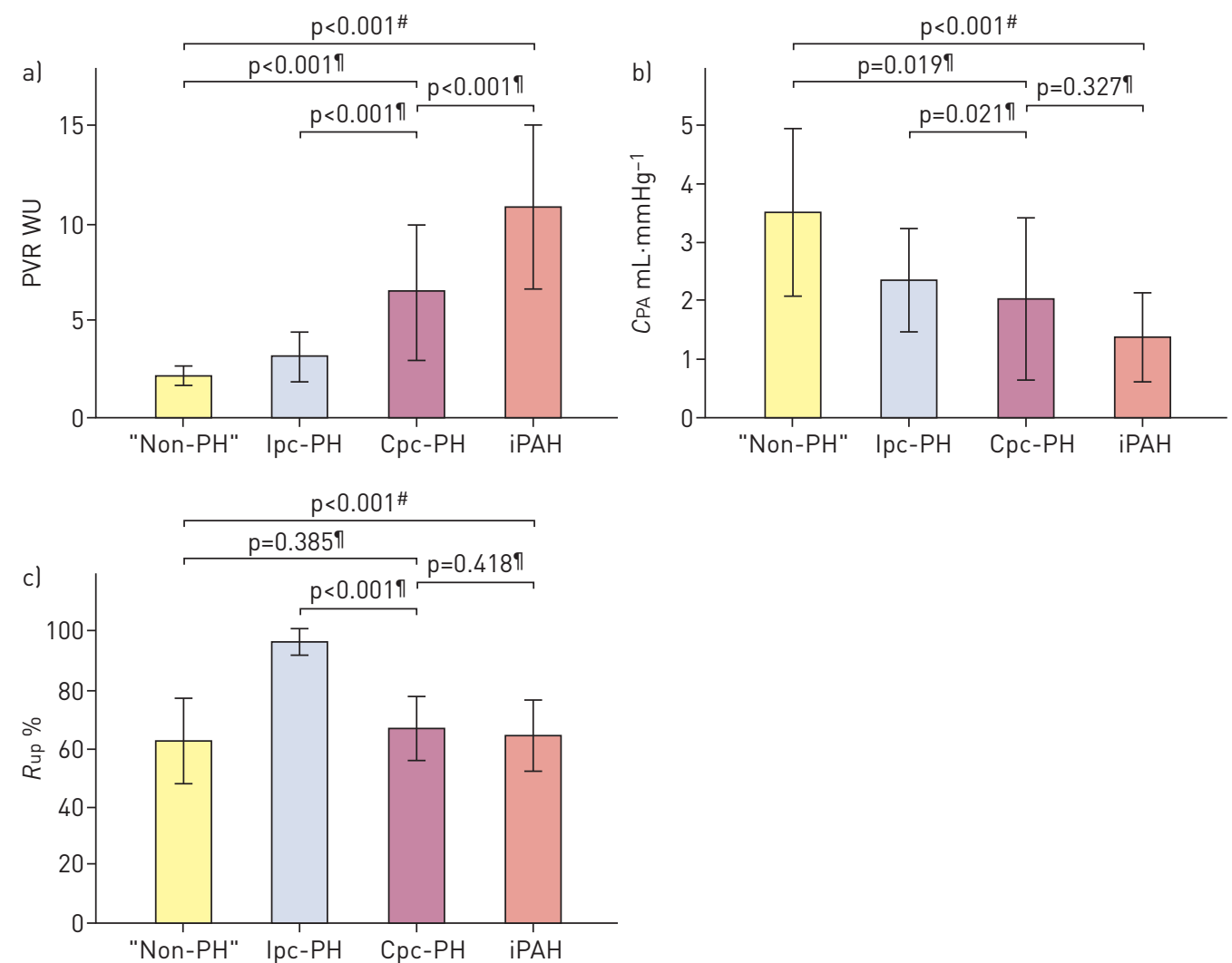

FIGURE 3 Right ventricular afterload and upstream resistance (Rup): a) pulmonary vascular resistance (PVR), b) pulmonary arterial compliance (CPA) and c) Rup in patients with normal pulmonary haemodynamics (without pulmonary hypertension ("Non-PH")), isolated post-capillary PH (Ipc-PH), combined post- and pre-capillary $\mathrm{PH}(\mathrm{Cpc}-\mathrm{PH})$, and idiopathic pulmonary arterial hypertension (iPAH). WU: Wood units. \#: one-way ANOVA with correction for multiple pairwise comparisons using the Bonferroni method; " : independent samples t-tests.

decrease in mPAP $(4 \pm 13 \%$; from $44.3 \pm 11.0$ to $42.3 \pm 11.2 \mathrm{mmHg} ; \mathrm{p}=0.056)$ did not reach statistical significance. In iPAH $(n=19)$, mPAP decreased by $6 \pm 9 \%$ (from $50.8 \pm 14.5$ to $47.5 \pm 15.0 \mathrm{mmHg} ; \mathrm{p}=0.004$ ), CO increased by $9 \pm 12 \%$ (from $4.5 \pm 1.2$ to $4.9 \pm 1.2 \mathrm{~L} \cdot \mathrm{min}^{-1}$; $\mathrm{p}=0.007$ ) and PVR decreased by $18 \pm 14 \%$ (from $10.3 \pm 5.3$ to $8.5 \pm 4.9 \mathrm{WU} ; \mathrm{p}=0.003)$.

\section{Discussion}

In this study, we examined detailed haemodynamics in PH-LHD patients and located the site of increased PVR by calculating Rup using the pulmonary artery occlusion technique. We also assessed changes in right ventricular afterload during inhalation of $\mathrm{NO}$ in PH-LHD. Rup is significantly lower in Cpc- $\mathrm{PH}$ than in Ipc-PH but resembles that in $\mathrm{PAH}$, consistent with the presence of pre-capillary pulmonary vascular disease in Cpc-PH. In contrast, the increase in PVR and PAP in Ipc-PH is driven by elevated LAP.

$P_{\mathrm{c}^{\prime}}$ is widely thought to reflect the pressure in small pulmonary arteries and capillaries [16-18], and should not exceed $16 \mathrm{mmHg}$ in healthy subjects [20]. Values $>20 \mathrm{mmHg}$ have been associated with pulmonary oedema [20]. Concordant with previous studies using monoexponential [19] and biexponential fitting of the PAP decay curve after balloon occlusion [16], we found that $P_{c^{\prime}}$ was markedly increased in iPAH compared with "Non-PH". $P_{c^{\prime}}$ was significantly higher in $\mathrm{Cpc}-\mathrm{PH}$ than in Ipc-PH (table 2). In Ipc-PH, the difference between $P_{\mathrm{c}^{\prime}}$ and $\mathrm{mPAWP}$ was negligible with a difference of $1.3 \pm 1.2 \mathrm{mmHg}$, and an almost perfect linear relationship between mPAWP and $P_{\mathrm{c}^{\prime}}(\mathrm{r}=0.989 ; \mathrm{p}<0.001)$, suggesting that $P_{\mathrm{c}^{\prime}}$ and mPAP elevation are determined by mPAWP. In contrast, the correlation between $P_{c^{\prime}}$ and mPAWP was only moderate in $\mathrm{Cpc}-\mathrm{PH}(\mathrm{r}=0.787 ; \mathrm{p}<0.001)$, similar to the findings in $\mathrm{iPAH}(\mathrm{r}=0.496 ; \mathrm{p}<0.001) . P_{\mathrm{c}^{\prime}}$ was significantly higher than $\mathrm{mPAWP}$ in $\mathrm{Cpc}-\mathrm{PH}$, suggesting an additional pre-capillary resistance component leading to an out-of-proportion increase in PAP (figure 6).

We located the site of increased PVR in $\mathrm{Cpc}-\mathrm{PH}$ by partitioning PVR into Rup and Rds using the pulmonary artery occlusion technique. $\mathrm{Cpc}-\mathrm{PH}$ showed the same pattern of PVR partitioning as iPAH (figure $3 \mathrm{c}$ ), with $\sim 60 \% R$ up and $\sim 40 \% R \mathrm{ds}$. The present findings are in agreement with histological 

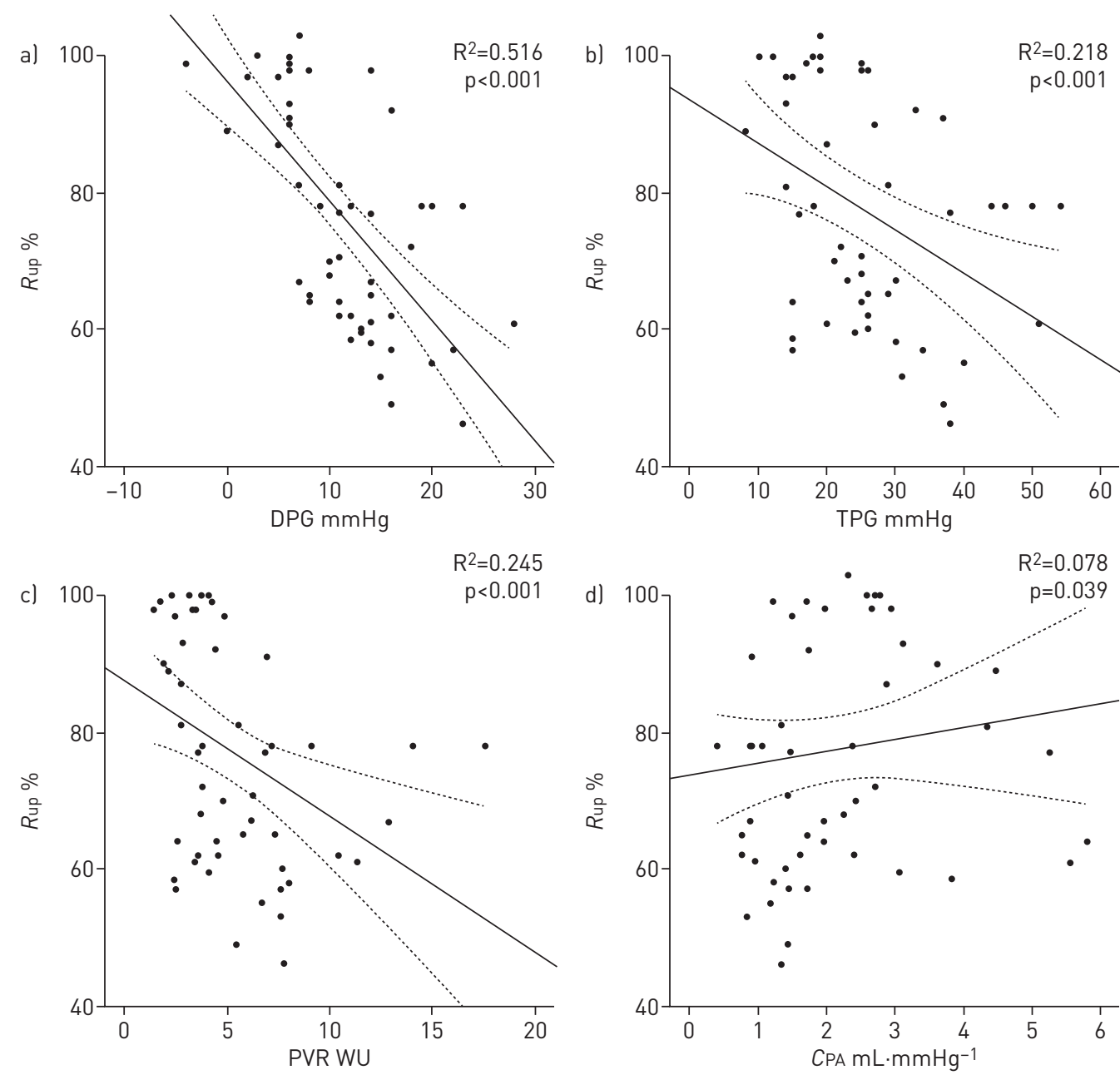

FIGURE 4 Relationship between upstream resistance (Rup) and parameters of right ventricular afterload in pulmonary hypertension due to left heart disease: a) diastolic pulmonary vascular pressure gradient (DPG), b) transpulmonary gradient (TPG), c) pulmonary vascular resistance (PVR) and d) pulmonary arterial compliance (CPA). WU: Wood units. Data are presented as means and $95 \%$ confidence intervals of the linear regression functions.

evidence of small vessel disease in $\mathrm{Cpc}-\mathrm{PH}$ resembling iPAH [2]. Ipc-PH showed very high Rup (figure 3c), indicating a passive increase in PVR and PAP driven by elevated left-sided filling pressures. To identify the best haemodynamic predictor of increased downstream stiffness and pulmonary vascular disease in PH-LHD, we performed regression analyses including PVR, CPA, TPG, DPG and Rup. We found a strong negative correlation between DPG and Rup, while TPG, PVR and CPA correlated only weakly with Rup (figure 4). Interestingly, Rup was not different between Ipc-PH patients with DPG $<7 \mathrm{mmHg}$ and PVR $\leqslant 3 \mathrm{WU}$ ( $\mathrm{n}=6$; Rup 96.9 $\pm 4.2 \%$; $\mathrm{p}=0.479$; supplementary figure SA) and those with $\mathrm{DPG}<7 \mathrm{mmHg}$ and PVR $>3$ WU ( $=14 ;$ Rup 95.3 $\pm 5.3 \%$ ). These results suggest that DPG appears to be more sensitive than PVR and CPA for the detection of changes in the downstream compartment, and might therefore be more meaningful for the definition of pulmonary vascular disease in PH-LHD.

Vasoreactivity in heart failure has been studied in the past using systemic infusions of nitrates and prostaglandin $\mathrm{E}_{1}[11,34-37]$. In a more recent study in patients with heart failure with reduced ejection fraction, greater improvements in PVR, DPG and TPG could be observed in Cpc-PH compared with Ipc- $\mathrm{PH}$ [11]. However, prostaglandin $\mathrm{E}_{1}$ and nitrates lower systemic blood pressure and increase $\mathrm{CO}$. We performed selective pulmonary vasoreactivity testing using iNO. Patients with $\mathrm{Cpc}-\mathrm{PH}$ showed significant improvements in right ventricular afterload during NO inhalation (table 2 and figure 5), but this was not the case in patients with Ipc-PH. The proportion of patients fulfilling classic haemodynamic responder criteria was similar in $\mathrm{Cpc}-\mathrm{PH}(8.6 \%)$ and $\mathrm{iPAH}$ (9.7\%). Interestingly, iNO led to significant improvements in right ventricular afterload in $\mathrm{Cpc}-\mathrm{PH}$ irrespective of haemodynamic responder status (supplementary table SA). These findings may explain the significant haemodynamic response of Cpc- $\mathrm{PH}$ 

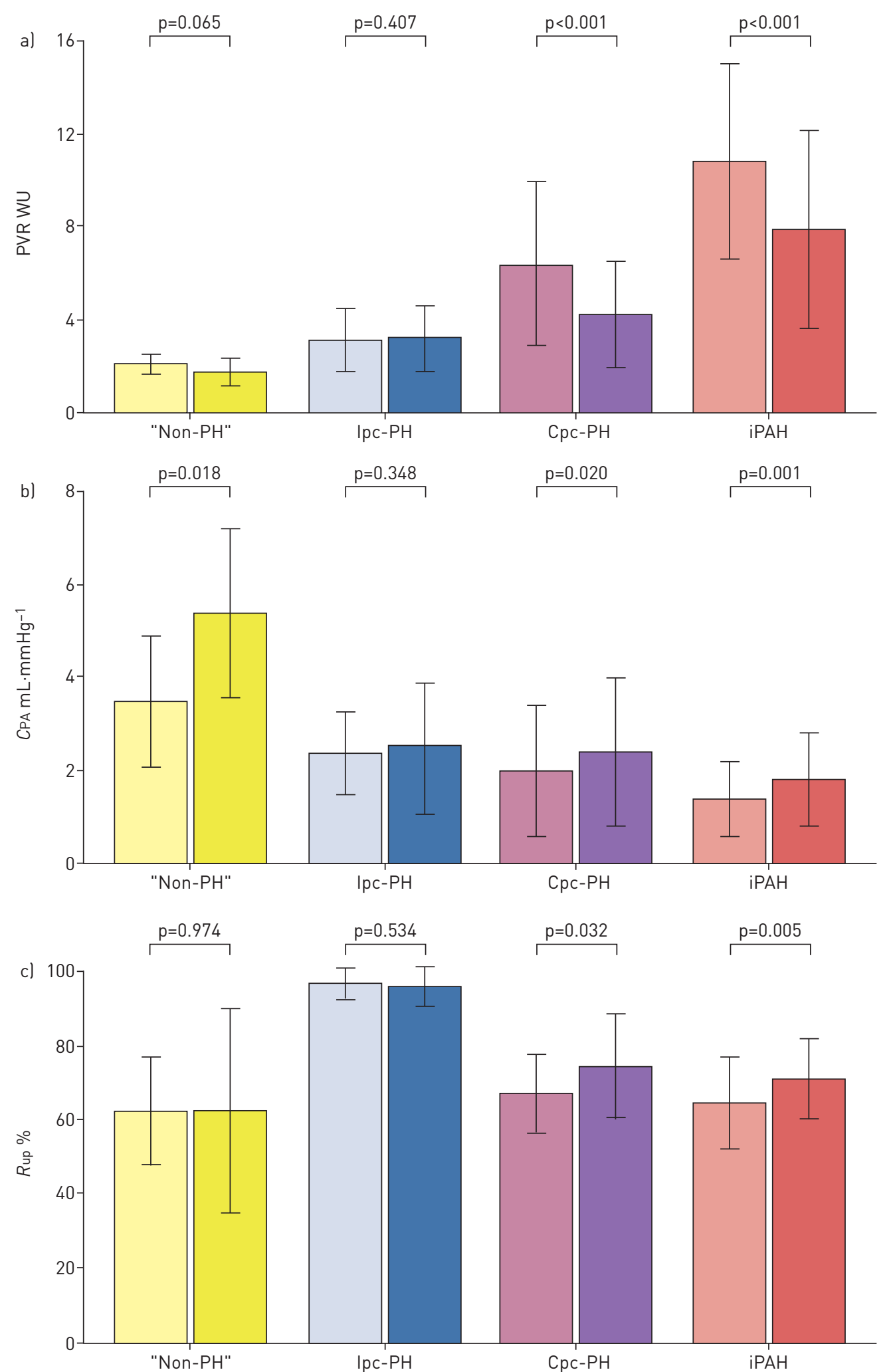

FIGURE 5 Effect of inhaled nitric oxide (iNO) on right ventricular afterload: a) pulmonary vascular resistance (PVR), b) pulmonary arterial compliance (CPA) and c) upstream resistance (Rup) at baseline (lighter bar in each columnl and after iNO (darker bar in each column) in patients with normal pulmonary haemodynamics (without pulmonary hypertension ("Non-PH")), isolated post-capillary PH (Ipc-PH), combined post- and pre-capillary $\mathrm{PH}(\mathrm{Cpc}-\mathrm{PH})$, and idiopathic pulmonary arterial hypertension (iPAH). WU: Wood units. All p-values are results from paired samples t-tests. 
a)

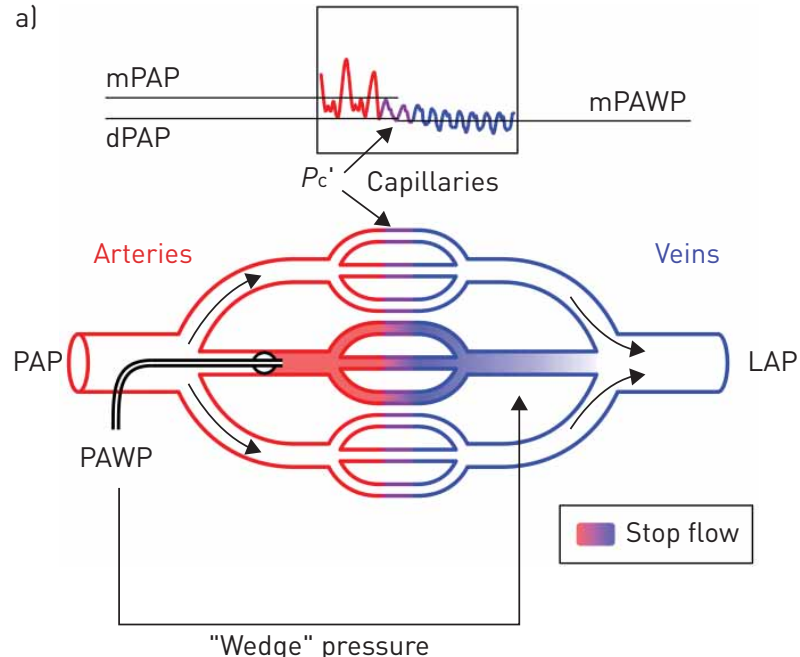

b)

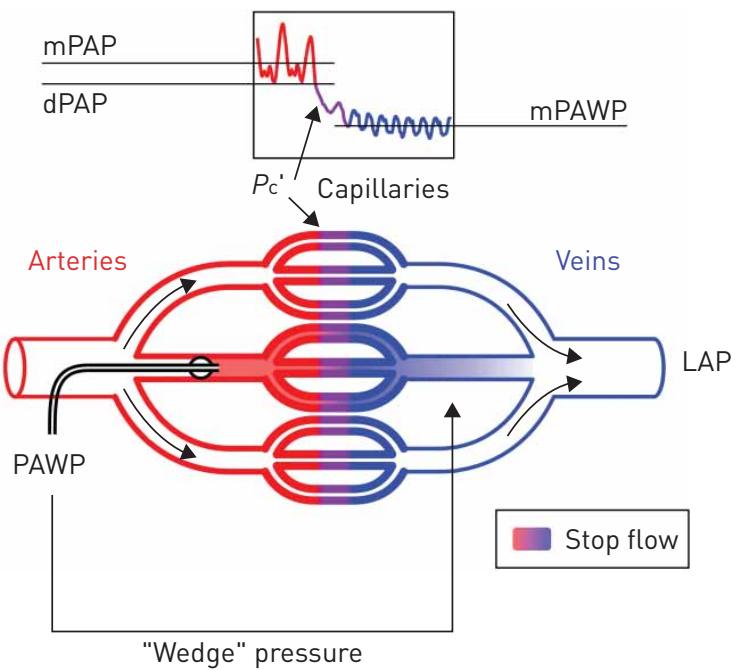

FIGURE 6 Models of the pulmonary circulation with corresponding phenotypes of pressure decay curves in a) isolated post-capillary pulmonary hypertension (Ipc-PH) and b) combined post- and pre-capillary PH (Cpc-PH). In Ipc-PH, there is a rapid decay from pulmonary arterial pressure (PAP) to pulmonary arterial wedge pressure (PAWP). The pressure in pre-capillary small pulmonary arteries and pulmonary capillaries $\left(P^{\prime}\right)$ is determined by left atrial pressure (LAP), and is at the same level as mean PAWP (mPAWP). In contrast, the pressure decay from PAP to PAWP is slow in $\mathrm{Cpc}-\mathrm{PH} . \mathrm{P}_{\mathrm{c}^{\prime}}$ is markedly elevated in comparison to mPAWP due to an additional component of pulmonary vascular disease at the level of small pulmonary arteries and capillaries. mPAP: mean PAP; dPAP: diastolic PAP. Upstream resistance Rup=(mPAP- $\left.\mathrm{c}^{\prime}\right) /(\mathrm{mPAP}-\mathrm{mPAWP}) \times 100$.

patients in the single positive randomised trial of sildenafil in PH-heart failure [38]. However, the study by GUAZZI et al. [38] was an exploratory trial with haemodynamic and echocardiographic end-points, and to date no positive randomised controlled trial with outcome data has been reported in PH-LHD [39-41]. Furthermore, in the recent randomised controlled MELODY-1 study, macitentan was associated with an increased incidence of significant fluid retention versus placebo in patients with $\mathrm{Cpc}-\mathrm{PH}$ [42]. In addition, macitentan resulted in no significant changes in N-terminal pro-brain natriuretic peptide and PVR.

\section{Limitations}

The number of patients with iPAH and $\mathrm{Cpc}-\mathrm{PH}$ in relation to Ipc-PH is overrepresented in this study, because the inclusion of patients with Ipc-PH was halted at a sample size of 20 patients, while inclusion of $\mathrm{iPAH}$ and $\mathrm{Cpc}-\mathrm{PH}$ patients was continued. Data from vasoreactivity testing of classic responders should be interpreted with caution because only three $\mathrm{Cpc}-\mathrm{PH}$ and three iPAH patients fulfilled the traditional haemodynamic responder criteria. Biexponential fitting of the decay curve may be affected by the presence of high "v" waves in PAWP tracings in case of atrial fibrillation and mitral regurgitation. In addition, arrhythmia in atrial fibrillation may alter the time-dependent algorithm for the derivation of $P_{c^{\prime}}$. Therefore, patients with atrial fibrillation and other forms of arrhythmia at the time of haemodynamic assessment were excluded from our analyses, and only one Cpc-PH patient and three Ipc-PH patients had significant mitral regurgitation.

Another problem is that many haemodynamic parameters, such as TPG, pulmonary pulse pressure, ejection fraction, $\mathrm{d} P / \mathrm{d} t_{\max }$, etc., are load dependent. For PVR it has been shown that the relationship between pressure gradient and flow is linear. Furthermore, modulation of flow and pressure using dobutamine infusion in dogs had no effect on the partitioning of PVR [43]. Hence, a change in loading conditions of the pulmonary vascular system does not seem to influence the evaluation of the upstream component of PVR. For TPG, a flow- and LAP-dependent increase has been described, while DPG has been shown to be rather insensitive to these haemodynamic variables [29].

\section{Conclusions}

Our data show that increased right ventricular afterload is driven by elevated LAP in Ipc-PH and aggravated by pulmonary small vessel disease in $\mathrm{Cpc}-\mathrm{PH}$. Cpc- $\mathrm{PH}$ is responsive to iNO. The easiest haemodynamic parameter to assess the presence of pulmonary vascular disease in PH-LHD is DPG, which may serve as a surrogate for Rup, while PVR should be used with caution. Taken together, our in-depth analysis provides physiological support for current definitions of PH-LHD subtypes.

Conflict of interest: C. Gerges reports grants from United Therapeutics Corporation, Bayer HealthCare and Actelion Pharmaceuticals, during the conduct of the study. He has also received personal fees (for scientific symposia) from 
GlaxoSmithKline, AOP Orphan and Actelion, outside the submitted work. M. Gerges reports grants from United Therapeutics Corporation, Bayer HealthCare and Actelion Pharmaceuticals, during the conduct of the study. He has also received personal fees (for scientific symposia) from GlaxoSmithKline, AOP Orphan and Actelion, outside the submitted work. P. Fesler reports personal fees (travel and accommodation support) from Actelion, outside the submitted work. I.M. Lang reports grants from United Therapeutics Corporation, Bayer AG and Actelion Pharmaceuticals, during the conduct of the study. She also received grants, personal fees and nonfinancial support from Actelion, AOP Orphan Pharmaceuticals, Bayer AG, GlaxoSmithKline, Pfizer and United Therapeutics Corporation, as well as honoraria from AstraZeneca, Servier, Cordis, Medtronic and Novartis, outside the submitted work.

Support statement: This research was funded by educational grants from Actelion Pharmaceuticals Ltd (00283GMS\&C), Bayer HealthCare Pharmaceuticals (15662) and United Therapeutics Corporation (REG-NC-002). Funding information for this article has been deposited with the Crossref Funder Registry.

\section{References}

1 Vachiery JL, Adir Y, Barbera JA, et al. Pulmonary hypertension due to left heart diseases. J Am Coll Cardiol 2013; 62: D100-D108.

2 Gerges C, Gerges M, Lang MB, et al. Diastolic pulmonary vascular pressure gradient: a predictor of prognosis in "out-of-proportion" pulmonary hypertension. Chest 2013; 143: 758-766.

3 Gerges C, Gerges M, Lang IM. Characterization of pulmonary hypertension in heart failure using the diastolic pressure gradient: the conundrum of high and low diastolic pulmonary gradient. JACC Heart Fail 2015; 3: $424-425$.

4 Gerges M, Gerges C, Pistritto AM, et al. Pulmonary hypertension in heart failure. epidemiology, right ventricular function, and survival. Am I Respir Crit Care Med 2015; 192: 1234-1246.

5 Naeije R, Gerges M, Vachiery JL, et al. Hemodynamic phenotyping of pulmonary hypertension in left heart failure. Circ Heart Fail 2017; 10: e004082.

6 Dragu R, Rispler S, Habib M, et al. Pulmonary arterial capacitance in patients with heart failure and reactive pulmonary hypertension. Eur J Heart Fail 2015; 17: 74-80.

7 Ibe T, Wada H, Sakakura K, et al. Pulmonary hypertension due to left heart disease: the prognostic implications of diastolic pulmonary vascular pressure gradient. J Cardiol 2016; 67: 555-559.

8 Rezaee ME, Nichols EL, Sidhu M, et al. Combined post- and precapillary pulmonary hypertension in patients with heart failure. Clin Cardiol 2016; 39: 658-664.

9 O'Sullivan CJ, Wenaweser P, Ceylan O, et al. Effect of pulmonary hypertension hemodynamic presentation on clinical outcomes in patients with severe symptomatic aortic valve stenosis undergoing transcatheter aortic valve implantation: insights from the new proposed pulmonary hypertension classification. Circ Cardiovasc Interv 2015; 8: e002358.

10 Yamabe S, Dohi Y, Fujisaki S, et al. Prognostic factors for survival in pulmonary hypertension due to left heart disease. Circ J 2016; 80: 243-249.

11 Ghio S, Crimi G, Temporelli PL, et al. Haemodynamic effects of an acute vasodilator challenge in heart failure patients with reduced ejection fraction and different forms of post-capillary pulmonary hypertension. Eur J Heart Fail 2018; 20: 725-734.

12 Palazzini M, Dardi F, Manes A, et al. Pulmonary hypertension due to left heart disease: analysis of survival according to the haemodynamic classification of the 2015 ESC/ERS guidelines and insights for future changes. Eur J Heart Fail 2018; 20: 248-255.

13 Tampakakis E, Leary PJ, Selby VN, et al. The diastolic pulmonary gradient does not predict survival in patients with pulmonary hypertension due to left heart disease. JACC Heart Failure 2015; 3: 9-16.

14 Tedford RJ, Beaty CA, Mathai SC, et al. Prognostic value of the pre-transplant diastolic pulmonary artery pressure-to-pulmonary capillary wedge pressure gradient in cardiac transplant recipients with pulmonary hypertension. J Heart Lung Transplant 2014; 33: 289-297.

15 Galiè N, Humbert M, Vachiery JL, et al. 2015 ESC/ERS Guidelines for the diagnosis and treatment of pulmonary hypertension: The Joint Task Force for the Diagnosis and Treatment of Pulmonary Hypertension of the European Society of Cardiology (ESC) and the European Respiratory Society (ERS). Eur Heart J 2016; 37: 67-119.

16 Fesler P, Pagnamenta A, Vachiery JL, et al. Single arterial occlusion to locate resistance in patients with pulmonary hypertension. Eur Respir J 2003; 21: 31-36.

17 Hakim TS, Michel RP, Chang HK. Partitioning of pulmonary vascular resistance in dogs by arterial and venous occlusion. J Appl Physiol Respir Environ Exerc Physiol 1982; 52: 710-715.

18 Hakim TS, Kelly S. Occlusion pressures vs. micropipette pressures in the pulmonary circulation. J Appl Physiol 1989; 67: 1277-1285.

19 Kafi SA, Melot C, Vachiery JL, et al. Partitioning of pulmonary vascular resistance in primary pulmonary hypertension. J Am Coll Cardiol 1998; 31: 1372-1376.

20 Maggiorini M, Melot C, Pierre S, et al. High-altitude pulmonary edema is initially caused by an increase in capillary pressure. Circulation 2001; 103: 2078-2083.

21 Kim NH, Fesler P, Channick RN, et al. Preoperative partitioning of pulmonary vascular resistance correlates with early outcome after thromboendarterectomy for chronic thromboembolic pulmonary hypertension. Circulation 2004; 109: 18-22.

22 Toshner M, Suntharalingam J, Fesler P, et al. Occlusion pressure analysis role in partitioning of pulmonary vascular resistance in CTEPH. Eur Respir J 2012; 40: 612-617.

23 Gerges C, Gerges M, Skoro-Sajer N, et al. Hemodynamic thresholds for precapillary pulmonary hypertension. Chest 2016; 149: 1061-1073.

24 Ponikowski P, Voors AA, Anker SD, et al. 2016 ESC Guidelines for the diagnosis and treatment of acute and chronic heart failure: The Task Force for the diagnosis and treatment of acute and chronic heart failure of the European Society of Cardiology (ESC). Developed with the special contribution of the Heart Failure Association (HFA) of the ESC. Eur Heart J 2016; 37: 2129-2200. 
25 Yancy CW, Jessup M, Bozkurt B, et al. 2013 ACCF/AHA guideline for the management of heart failure: a report of the American College of Cardiology Foundation/American Heart Association Task Force on Practice Guidelines. J Am Coll Cardiol 2013; 62: e147-e239.

26 Kovacs G, Avian A, Pienn M, et al. Reading pulmonary vascular pressure tracings. How to handle the problems of zero leveling and respiratory swings. Am J Respir Crit Care Med 2014; 190: 252-257.

27 Hemnes AR, Trammell AW, Archer SL, et al. Peripheral blood signature of vasodilator-responsive pulmonary arterial hypertension. Circulation 2015; 131: 401-409.

28 Harvey RM, Enson Y, Ferrer MI. A reconsideration of the origins of pulmonary hypertension. Chest 1971; 59: 82-94.

29 Naeije R, Vachiery JL, Yerly P, et al. The transpulmonary pressure gradient for the diagnosis of pulmonary vascular disease. Eur Respir J 2013; 41: 217-223.

30 Lankhaar JW, Westerhof N, Faes TJ, et al. Quantification of right ventricular afterload in patients with and without pulmonary hypertension. Am J Physiol Heart Circ Physiol 2006; 291: H1731-H1737.

31 Baconnier PF, Eberhard A, Grimbert FA. Theoretical analysis of occlusion techniques for measuring pulmonary capillary pressure. J Appl Physiol 1992; 73: 1351-1359.

32 Pagnamenta A, Bouckaert Y, Wauthy $\mathrm{P}$, et al. Continuous versus pulsatile pulmonary hemodynamics in canine oleic acid lung injury. Am J Respir Crit Care Med 2000; 162: 936-940.

33 Gerges M, Gerges C, Lang IM. How to define pulmonary hypertension due to left heart disease. Eur Respir J 2016; 48: 553-555.

34 Gavazzi A, Ghio S, Scelsi L, et al. Response of the right ventricle to acute pulmonary vasodilation predicts the outcome in patients with advanced heart failure and pulmonary hypertension. Am Heart J 2003; 145: 310-316.

35 Goland S, Czer LS, Kass RM, et al. Pre-existing pulmonary hypertension in patients with end-stage heart failure: impact on clinical outcome and hemodynamic follow-up after orthotopic heart transplantation. J Heart Lung Transplant 2007; 26: 312-318.

36 Preston IR, Sagliani KD, Roberts KE, et al. Comparison of acute hemodynamic effects of inhaled nitric oxide and inhaled epoprostenol in patients with pulmonary hypertension. Pulm Circ 2013; 3: 68-73.

37 von Scheidt W, Costard-Jaeckle A, Stempfle HU, et al. Prostaglandin $\mathrm{E}_{1}$ testing in heart failure-associated pulmonary hypertension enables transplantation: the PROPHET study. J Heart Lung Transplant 2006; 25: $1070-1076$.

38 Guazzi M, Vicenzi M, Arena R, et al. Pulmonary hypertension in heart failure with preserved ejection fraction: a target of phosphodiesterase-5 inhibition in a 1-year study. Circulation 2011; 124: 164-174.

39 Bonderman D, Ghio S, Felix SB, et al. Riociguat for patients with pulmonary hypertension caused by systolic left ventricular dysfunction: a phase IIb double-blind, randomized, placebo-controlled, dose-ranging hemodynamic study. Circulation 2013; 128: 502-511.

40 Bonderman D, Pretsch I, Steringer-Mascherbauer R, et al. Acute hemodynamic effects of riociguat in patients with pulmonary hypertension associated with diastolic heart failure (DILATE-1): a randomized, double-blind, placebo-controlled, single-dose study. Chest 2014; 146: 1274-1285.

41 Hoendermis ES, Liu LC, Hummel YM, et al. Effects of sildenafil on invasive haemodynamics and exercise capacity in heart failure patients with preserved ejection fraction and pulmonary hypertension: a randomized controlled trial. Eur Heart J 2015; 36: 2565-2573.

42 Vachiery JL, Delcroix M, Al-Hiti H, et al. Macitentan in pulmonary hypertension due to left ventricular dysfunction. Eur Respir J 2018; 51: 1701886.

43 Pagnamenta A, Fesler P, Vandinivit A, et al. Pulmonary vascular effects of dobutamine in experimental pulmonary hypertension. Crit Care Med 2003; 31: 1140-1146. 